\title{
EFFECTS OF WILDFIRE SUPPRESSION CHEMICALS ON PEOPLE AND THE ENVIRONMENT - A REVIEW
}

KOSTAS D. KALABOKIDIS

Received: 01/11/99

Accepted: $27 / 09 / 00$

\author{
University of the Aegean \\ Department of Geography \\ GR - 81100 Mytilene, Greece
}

e-mail: kalabokidis@aegean.gr

tel.: +30-251-36 455; fax: +30-251-36 459

\section{ABSTRACT}

Fire agencies worldwide apply millions of gallons of fire suppression chemicals on a broad array of ecosystems. These chemicals are considered to have minimal effects on the health of people who might be exposed to them. Only incidents of skin and eye irritation have been reported as a result of prolonged fire retardant and firefighting foam contact. Fire suppression chemicals have minor toxicological or ecological effects and, as a result, do not generally harm terrestrial ecosystems. Major impacts, suppression chemicals have on the environment, may be through the adverse effects on water quality, and subsequently to aquatic ecosystems. Retardants may encourage eutrophication and, in some cases, contribute to fish kill when applied on watersheds, or if accidentally applied directly to water bodies. Foams are generally more toxic than retardants to aquatic biota, but they are applied in much smaller quantities. Application of retardants increases the total amount of smoke and airborne particulate produced, but air quality implications are minimal since additional smoke emission by the retardant is insignificant compared to the major output by the wildfire. Recommendations are offered for mitigation of potential human health and environmental impacts from the use of fire suppression chemicals, nevertheless, risks must be assessed on a site-by-site basis.

KEY WORDS: Fire retardants, firefighting foams, environmental pollution, risk assessment.

\section{INTRODUCTION}

A variety of chemicals have been increasingly in use on wildland fire suppression since the 1930s. These chemicals have proved to be an effective firefighting tool for retarding the spread and lowering the intensity of wildfires. Chemicals have uses in direct ways to attack fires (in treatment of burning fuels) and indirect attack (in advance of a fire front to create control lines or to reinforce constructed firelines in the unburned fuel); they are also used in fire prevention and safe conduct of prescribed burning (Pyne et al., 1996).

Chemical retardation of a wildfire works by lowering the temperature of the fuel so that it will slowly burn only by glowing combustion, not by flaming; this is accomplished by injecting flameinhibiting agents into the combustion zone. The end result is a decrease of the total heat output by as much as $35 \%$ and drastic reduction of the zone in which new ignitions occur (Blakely, 1990).

Fire suppression chemicals include long-term fire retardants (inhibit combustion even after the loss 
of their watery matrix), short-term retardants (their effectiveness vanishes with the evaporation of water), firefighting foams (form small bubbles when mixed with water) and wetting agents (reduce the surface tension of water and increase its spreading ability) that may be applied aerially using airtankers and helicopters or from the ground using engine-powered pumps (Hardy, 1977; NWCG Fire Equipment Working Team, 1993, 1995b). State-of-the-art on the role and application of these chemical formulations in fire suppression operations is documented in several comprehensive surveys (Hardy, 1977; Johnson and George, 1990; NWCG Fire Equipment Working Team, 1992, 1993, 1995a, 1995b). The purpose of this paper is to summarize the potential health effects of human exposures to existing wildfire suppression chemicals and to provide an assessment of the ecological impacts associated with the introduction of these chemicals into natural ecosystems.

\section{PROBLEM SYNTHESIS}

Retardants are basically mixtures of water and selected inorganic salts (fertilizers) with a few additives to thicken (clays and gums), to inhibit corrosion and spoilage (bactericides), and to color the liquid (dyers). The flame-retarding compounds are based on a number of chemical elements (phosphorus, sulphur, antimony, chlorine, bromine, boron and nitrogen), which have the potential to cause adverse human health and environmental effects when applied too heavily or indiscriminately. For example, borate salts (early version retardants) were found to have undesirable side effects with soil sterilization and high toxicity levels, and are no longer in use.

Active chemicals in modern retardants (e.g., ammonium sulfates $\left[\left(\mathrm{NH}_{4}\right)_{2} \mathrm{SO}_{4}\right]$ and diammonium phosphates $\left.\left[\left(\mathrm{NH}_{4}\right)_{2} \mathrm{HPO}_{4}\right]\right)$ are like agricultural fertilizers, but need to receive more attention regarding possible health and ecosystem impacts; incidents of misapplication and adverse environmental effects are well within the realm of reality, even with compounds of inherent low toxicity.

Wildland fire chemicals may come in contact with all constituents of the environment, i.e., soil, water, air, and all plant and animal life therein, including people. The effect of this contact, being infrequent and on non-periodic basis, will depend on the total retardant application amount, area covered and site-specific characteristics. Hence, all environmental considerations and potential ecological effects from these chemical compounds should be focused on the above ecosystem components and the retardant critical properties.

\section{EFFECTS ON HUMANS}

The chemicals used in wildland fire suppression are considered to have minimal effects on the health of people who might be exposed to them. Most of the ingredients in the formulations are common chemicals found in fertilizers, household cleansers, soaps, cosmetics, paints, and as preservatives in prepared food products. Only incidents of skin and eye irritation have been reported as a result of prolonged retardant contact, with greatest potential danger entailed around the mixing base and only if an unusual incident occurs (e.g., retardant ingestion). No cases of systematic toxicity have been revealed (Hardy, 1977).

Fire suppressant foams have health effects similar to those of common household soaps and shampoos. Foam concentrates are strong detergents and care should be taken to avoid exposure of the skin to the concentrate, especially for long periods of time and for people having allergic reactions to such substances. Failure to follow safe handling instructions may result in extreme skin dryness, characterized by chapping and even broken skin. The eyes are potentially the biggest problem; they are sensitive to detergents and the alcohol that is contained in some formulations. Eye irritation and redness may be mild to severe. Dizziness may also occur and take several days to subside. Presently there is no evidence to suggest that foams or their constituents have any carcinogenic, reproductive, or mutagenic effects (NWCG Fire Equipment Working Team, 1993).

A quantitative assessment of the human health risks, associated with exposure to fire suppression chemicals, was prepared by Labat-Anderson Inc. (1994a). Hazard analysis was conducted for each chemical to determine an acceptable dose level, and this level was compared to the estimated doses to fire workers and members of the public for average (i.e., typical wildfire season) and upper end (i.e., high wildfire season) exposure scenarios. There was significant uncertainty in this analysis, primarily due to the limited toxicity database available. In addition, none of the fire 
suppression chemical formulations had been tested as a whole for carcinogenicity, and therefore no cancer risk analysis was done. However, analysis for suspected individual chemical ingredients revealed negligible cancer risks, without any significant orders of magnitude. During the many years of use of long- and short-term fire retardants, no links have been established between human exposure and cancer (Labat-Anderson Inc., 1994c).

Toxicity levels (oral median lethal dose, $\mathrm{LD}_{50}$, and acceptable daily intake, ADI) for each formulation are presented in Table 1 and provide thresholds that can be tolerated with little potential for adverse health effects. The likelihood of non-carcinogenic health effects is given as a hazard quotient (obtained as a simple ratio between the estimated dose and the acceptable daily intake) for two human groups at risk of exposure to wildland fire suppression chemicals exposure (LabatAnderson Inc., 1994a). For each chemical, Table 2 presents these risks to firefighters and overhead personnel, and Table 3 presents risks to adult and child spectators after an accidental drench. There is a potential risk of non-carcinogenic health effects if the hazard quotient exceeds 1, i.e., if the estimated dose exceeds the acceptable level of exposure (Labat-Anderson Inc., 1994a).

Table 1. Lethal toxicity values $\left(\mathrm{LD}_{50}\right)$ and acceptable daily intakes (ADI) for wildland fire suppression chemicals

\begin{tabular}{|c|c|c|}
\hline CHEMICAL & Oral LD50 (mg kg-1) & Estimated ADI (mg kg-1 day $\left.^{-1}\right)$ \\
\hline \multicolumn{3}{|l|}{ Long-Term Retardants } \\
\hline Fire-Trol GTS-R & $>4330$ & 0.220 \\
\hline Phos-Chek D75-R & $>5050$ & 0.250 \\
\hline Phos-Chek D75-F & $>5000$ & 0.250 \\
\hline Phos-Chek 259F & 3100 & 0.160 \\
\hline Phos-Chek G75-W & 4200 & 0.210 \\
\hline Phos-Chek G75-F & 4200 & 0.210 \\
\hline Phos-Chek HV-R & $>5050$ & 0.250 \\
\hline Fire-Trol LCA-R & $>505$ & 0.025 \\
\hline Fire-Trol LCG-R & $>5050$ & 0.250 \\
\hline Fire-Trol LCG-F & $>5000$ & 0.250 \\
\hline Phos-Chek MV-R & $>5050$ & 0.025 \\
\hline Phos-Chek MV-F & $>5050$ & 0.250 \\
\hline Phos-Chek HV-F & $>5050$ & 0.250 \\
\hline \multicolumn{3}{|l|}{ Short-Term Retardants } \\
\hline Fire-Trol ST-F & $>5050$ & 0.250 \\
\hline Fire-Trol STH-F & $>500$ & 0.025 \\
\hline Fire-Trol ST2-V & $>5050$ & 0.250 \\
\hline \multicolumn{3}{|l|}{ Foams } \\
\hline Phos-Chek WD 861 & $>5000$ & 0.250 \\
\hline Ansul Silv-Ex & $>5050$ & 0.250 \\
\hline Fire-Trol FireFoam 103B & $>5050$ & 0.250 \\
\hline Phos-Chek WD 881 & $>5000$ & 0.250 \\
\hline Fire-Trol FireFoam 104 & $>5050$ & 0.250 \\
\hline Angus ForEpan S & 4767 & 0.240 \\
\hline Pyrocap B-136 & $>5050$ & 0.250 \\
\hline \multicolumn{3}{|l|}{ Wetting Agents } \\
\hline FireChem & No data & No data \\
\hline KCR & No data & No data \\
\hline
\end{tabular}

Source: Labat-Anderson Inc., 1994a 
Table 2. Non-carcinogenic health risks to firefighters and overhead personnel from wildland fire suppression chemicals; hazard quotients that exceed 1 are bolded [Hazard Quotient $=$ Dose $\left(\mathrm{mg} \mathrm{kg}^{-1} \mathrm{day}^{-1}\right) /$ Acceptable Daily Intake $\left(\mathrm{mg} \mathrm{kg}^{-1}\right.$ day $\left.\left.^{-1}\right)\right]$.

\begin{tabular}{|l|c|c|c|}
\hline \multirow{2}{*}{ CHEMICAL } & \multicolumn{3}{|c|}{ Hazard Quotient } \\
\cline { 2 - 4 } & Average & Upper End & Drench \\
\hline Long-Term Retardants & & & \\
Fire-Trol GTS-R & 0.000021 & 0.000064 & $\mathbf{2 . 8 0}$ \\
Phos-Chek D75-R & 0.000013 & 0.000040 & $\mathbf{1 . 7 0}$ \\
Phos-Chek D75-F & 0.000013 & 0.000040 & $\mathbf{1 . 8 0}$ \\
Phos-Chek 259F & 0.000021 & 0.000062 & $\mathbf{2 . 7 0}$ \\
Phos-Chek G75-W & 0.000015 & 0.000045 & $\mathbf{1 . 9 0}$ \\
Phos-Chek G75-F & 0.000015 & 0.000045 & $\mathbf{1 . 9 0}$ \\
Phos-Chek HV-R & 0.000028 & 0.000084 & $\mathbf{3 . 7 0}$ \\
Fire-Trol LCA-R & 0.000025 & 0.000076 & $\mathbf{3 . 3 0}$ \\
Fire-Trol LCG-R & 0.000023 & 0.000069 & $\mathbf{3 . 0 0}$ \\
Fire-Trol LCG-F & 0.000023 & 0.000070 & $\mathbf{3 . 4 0}$ \\
Phos-Chek MV-R & 0.000026 & 0.000077 & $\mathbf{3 . 3 0}$ \\
Phos-Chek MV-F & 0.000025 & 0.000075 & $\mathbf{3 . 7 0}$ \\
Phos-Chek HV-F & 0.000028 & 0.000084 & \\
\hline Short-Term Retardants & & & 0.16 \\
Fire-Trol ST-F & 0.000012 & 0.0000037 & $\mathbf{2 . 1 0}$ \\
Fire-Trol STH-F & 0.000016 & 0.0000480 & 0.16 \\
Fire-Trol ST2-V & 0.000012 & 0.0000037 & 0.21 \\
\hline Foams & & & 0.21 \\
Phos-Chek WD 861 & 0.00016 & 0.00048 & 0.20 \\
Ansul Silv-Ex & 0.00016 & 0.00047 & 0.21 \\
Fire-Trol FireFoam 103B & 0.00016 & 0.00047 & No data \\
Phos-Chek WD 881 & 0.00016 & 0.00048 & 0.00047 \\
Fire-Trol FireFoam 104 & 0.00016 & 0.0005 & 0.00049 \\
Angus ForEpan S & 0.00017 & & No data \\
Pyrocap B-136 & 0.00016 & No data & \\
\hline Wetting Agents & & & \\
FireChem & No data & data & \\
KCR & & & \\
\hline
\end{tabular}

Source: Labat-Anderson Inc., 1994a

For firefighters and overhead personnel walking through wet retardant on vegetation and exposure to aerial drops of chemicals, both average and upper end conditions are predicted to result in negligible risks from all currently approved wildfire chemicals (Table 2). The estimated exposure to these workers being in the path of chemical application and being drenched by the diluted mixture results in a hazard quotient greater than 1 for all long-term retardants and the short-term retardant Fire-Trol STH-F (Table 2). As was the case for workers, both children and adults were estimated to have a hazard quotient greater than 1 as a result of being in the path of an aerial application of any long-term retardant and the short-term retardant Fire-Trol STH-F, indicating appreciable risks (Table 3). 
Table 3. Non-carcinogenic health risks to the public from an accidental fire suppression chemical drench; hazard quotients that exceed 1 are bolded [Hazard Quotient $=$ Dose $\left(\mathrm{mg} \mathrm{kg}^{-1}\right.$ day $\left.^{-1}\right) /$ Acceptable Daily Intake $\left.\left(\mathrm{mg} \mathrm{kg}^{-1} \mathrm{day}^{-1}\right)\right]$.

\begin{tabular}{|l|c|c|}
\hline \multirow{2}{*}{ CHEMICAL } & \multicolumn{2}{|c|}{ Hazard Quotient } \\
\cline { 2 - 3 } & Adult & Child \\
\hline Long-Term Retardants & & \\
Fire-Trol GTS-R & 2.60 & $\mathbf{2 . 9 0}$ \\
Phos-Chek D75-R & 1.60 & $\mathbf{1 . 8 0}$ \\
Phos-Chek D75-F & 1.60 & $\mathbf{1 . 8 0}$ \\
Phos-Chek 259F & 2.50 & $\mathbf{2 . 8 0}$ \\
Phos-Chek G75-W & 1.80 & $\mathbf{2 . 0 0}$ \\
Phos-Chek G75-F & 1.80 & $\mathbf{2 . 0 0}$ \\
Phos-Chek HV-R & 3.40 & $\mathbf{3 . 8 0}$ \\
Fire-Trol LCA-R & 3.10 & $\mathbf{3 . 5 0}$ \\
Fire-Trol LCG-R & 2.80 & $\mathbf{3 . 2 0}$ \\
Fire-Trol LCG-F & 2.80 & $\mathbf{3 . 2 0}$ \\
Phos-Chek MV-R & 3.10 & $\mathbf{3 . 5 0}$ \\
Phos-Chek MV-F & 3.10 & $\mathbf{3 . 4 0}$ \\
Phos-Chek HV-F & 3.40 & $\mathbf{3 . 8 0}$ \\
\hline Short-Term Retardants & & \\
Fire-Trol ST-F & 0.15 & 0.17 \\
Fire-Trol STH-F & 2.00 & $\mathbf{2 . 2 0}$ \\
Fire-Trol ST2-V & 0.15 & 0.17 \\
\hline Foams & & \\
Phos-Chek WD 861 & 0.20 & 0.22 \\
Ansul Silv-Ex & 0.19 & 0.21 \\
Fire-Trol FireFoam 103B & 0.19 & 0.22 \\
Phos-Chek WD 881 & 0.20 & 0.22 \\
Fire-Trol FireFoam 104 & 0.19 & 0.22 \\
Angus ForEpan S & 0.20 & 0.23 \\
Pyrocap B-136 & 0.20 & No data \\
\hline Wetting Agents & No data & \\
FireChem & & \\
KCR & & \\
Sourc: Lata & \\
\hline & & \\
\hline & & \\
\hline & & \\
\hline
\end{tabular}

Source: Labat-Anderson Inc., 1994a

Other potential risks from fire suppression chemicals are the physical impacts on people. For example, aerially delivered retardant not yet broken into raindrops or mist can, and has been, fatal for personnel being directly in the path of the drop. Also, retardants are slippery and create serious footing hazards when spilled.

\section{ENVIRONMENTAL IMPACTS}

Fire management agencies utilize millions of gallons of chemicals on a wide array of ecosystems.
These chemicals are often applied in environmentally sensitive areas that may contain endangered, threatened, or economically significant plant and animal species. Relatively little information is available on the toxicity of these chemicals to aquatic and terrestrial life. Less information is available concerning impacts at the community and ecosystem level. In addition, the potential harmful effects of suppression chemicals versus a catastrophic wildfire may be difficult to differentiate, and depend on many fire- and 
site-specific variables.

The ammonium $\left(\mathrm{NH}_{4}\right)$, phosphate $\left(\mathrm{PO}_{4}\right)$ and sulfate $\left(\mathrm{SO}_{4}\right)$ radicals are the chemicals in retardant solutions most likely to cause changes in the local environment. Ammonium is available to the plants directly and/or indirectly (as nitrite and nitrate). Some ammonium may be denitrified (evaporated as nitrogen gas) and some may leach away to ground water or streams. Expansive clays can also trap a portion of ammonium. The phosphate radical can be taken up directly by plants (in $20 \%$ efficiency) and indirectly (converted chemically into available forms), or be lost in soil water. The sulfate radical lowers soil $\mathrm{pH}$ by forming sulfate acid, causing elements such as iron, copper, zinc and manganese to become more readily soluble (Hardy, 1977).

\section{Terrestrial ecosystems}

Fire suppression chemicals do not generally harm terrestrial wildlife, vegetation and soils. The extensively used ammonium formulations have long been considered to have minimal toxicological or ecological effects. In fact, long-term retardants may benefit wildlife because of increased growth to trees, plants and grasses, since these chemicals are composed mostly of fertilizers. In rare occasions, an overdose application of retardant can be damaging to plants; free ammonia $\left(\mathrm{NH}_{3}\right)$ may also be highly toxic in soils having low cation exchange capacities and low microbial activity. These risks, however, are small in scale and are not likely to have lasting effects.

Only one study in an Australian eucalyptus forest, which was sprayed with an ammonium sulfate compound, described phytotoxic short-term effects to vegetation (widespread leaf death in tree, shrub and ground cover species). However, this effect was poorly documented and did not appear to be a major issue of concern (Bradstock et al., 1987). The lack of other references documenting phytotoxic effects suggests that phytotoxicity is not a major concern.

Use of fire suppression chemicals may cause increased foraging opportunities (like the fire itself). A project in a California grassland found that application of diammonium phosphate produced almost twice the yield of forage in the first year after application in both burned and unburned areas; no phytotoxicity was reported (Larson and Duncan, 1982). Studies currently being conducted show that fire chemicals may result in decreases in species richness and diversity, but these effects need further investigation. The potential risk of terrestrial large animals from fire retardant materials is minimal, much less than that from range or pasture fertilization. Smaller herbivores, such as mice, moles and other animals that often play an important role in an ecosystem, may be susceptible to slight increase in nitrate accumulations in the plants they utilize.

Ammonia-containing retardants may indirectly cause nitrate poisoning to herbivorous mammals from increased nitrate uptakes by grazing plants. The process of nitrate uptake by plants requires two to three weeks and happens only in unusual conditions of low light and high temperatures, and when drought occurs late in the growing season. Even under these circumstances, the total effect would be small, as the areas covered by retardant drop are narrow and the nitrate-contaminated forage is only a small part of the diet of the large mammals most affected (Hardy, 1977; Labat-Anderson Inc., 1994b).

Risk assessment for the toxicity of long-term retardants to terrestrial wildlife indicated possible adverse effects only to blue jays (Cyanocitta cristata), wild turkeys (Melagris gallopavo), quail (Callipela spp.), rabbits (Lepus spp.), and deer (Odocoileus spp.). No harm effects to terrestrial species were detected by the risk estimates for firefighting foams. Finally, the likelihood of physical injury to terrestrial species from applications of fire suppression chemical is remote, since large animals leave the area of a fire and small mammals seek shelter in burrows (Labat-Anderson Inc., 1994c).

\section{Aquatic ecosystems}

Evidence shows that the major impact fire suppression chemicals have on the environment may be through the adverse effects on water quality, and subsequently to fresh water fish and other stream biota. Many of the ions are lethal to aquatic life at the concentrations found in modern fire chemicals (Norris et al., 1978).

Ammonia appears to be the most toxic of all ions in fire chemical compounds, affecting certain invertebrate aquatic organisms (such as shrimp) and the egg-sac fry of certain vertebrates (such as salmon and trout; Blahm and Snyder, 1974). These chemicals may encourage eutrophication 
and, in some cases, contribute to fish kill when applied on watersheds, or if accidentally applied directly to a body of water.

Fire chemicals applied to wildland ecosystems may be washed away through overland flow during intense storms (surface runoff), or leached into the soil profile (leaching) and carried through subsurface drainage channels to streams or other water bodies. Losses of nitrate, ammonia, organic nitrogen, or phosphate to stream flow due to leaching or runoff of chemicals are seldom substantial enough to have a prolonged damaging effect.

Direct application of retardant causes the most immediate and greatest effect on the water, but it is probably the most transitory. The degree of impact of chemicals on aquatic species depends on site-specific characteristics, such as the steepness of the surrounding land and the size of the stream. Three types of stream organisms can indicate the toxic effect of introduced materials such as fire chemicals, i.e., benthic organisms, drift organisms and distressed fish (Hardy, 1977).

Retardant toxic concentration and duration of exposure affect inversely the ability of a fish to survive. The concentration of free ammonia in any water mixture is directly proportional to the amount of ammonium contained in the retardant, and the temperature and $\mathrm{pH}$ of the receiving water body. A large watercourse can afford escape areas of uncontaminated waters; large water volume increases the dilution rate and reduces the toxicity factor (Norris et al., 1978). Van Meter and Hardy (1975) proposed a computation system that permits a rapid estimate of the hazard to game fish caused by release of fire retardant into streams. On an operational basis, this method can be applied as a part of fire planning and suppression operations, and as an assessment of the effects of an accidental release of fire retardant into a stream.

In conclusion, aquatic ecosystems are more at risk from fire suppression chemicals than are terrestrial ecosystems; these risks, however, are not easily quantified. Salmonids as a group are more sensitive to long-term retardants than other fish species, and fish at the swim-up stage is more sensitive than either eggs or adults. There is less difference in toxicity among fish species for foams; firefighting foams are generally more toxic than long-term retardants to fish and other aquatic life, but they are applied in much smaller quantities. Actual risks from fire suppression chemicals must be assessed on a site-by-site basis, depending on local characteristics (Labat-Anderson Inc., 1994b).

\section{Air quality}

During application of retardant some ammonia gas is released, which can cause momentarily breathing difficulties and irritation of throat and lungs, but no toxic harm is likely. Application of retardants increases the total amount of smoke and airborne particulate produced, because of incomplete combustion. However, the low toxicity levels of retardants make the chances remote for additional damages from breathing the smoke of retardant-treated burning fuels.

Ammonium phosphate retardants reduce glowing combustion and lead to an increase in smoke; ammonium sulfate retardants leave virtually no residue, thus reducing slightly the total amount of smoke production. This phenomenon leads to more black smoke produced by phosphate- than sulfate-based retardants. These implications are more important on small than large fires, because additional smoke emission by the retardant is insignificant compared to the total output by the big wildfire (Hardy, 1977).

Aircraft crews from CL-215 waterbombers (George, 1975), which were applying firefighting foams, complained of eye and nasal irritation during operations. Sampling results inside the aircraft before-during-and-after actual and test fire operations were inconclusive as to which chemicals were causing the problem. Concentrations of present organic compounds (hexylene glycol, isopropyl alcohol, and toluene) were found to be between $1-10 \%$ of the threshold limits and unlikely to have caused the adverse effect. The odor of the mixture may have caused the effects, and hence, improved ventilation of the aircraft cabins may offer the solution (Petherick, 1990).

\section{SUMMARY AND CONCLUSIONS}

Personal safety and public health should be a priority when fire suppression chemicals are applied. Personnel must follow the safe handling instructions as found on the product label and material safety data sheet. To eliminate possible health problems the following precautions should be taken: 
- for irritant alleviation wash skin, irrigate eyes with clean water, replace soaked clothes, apply hand or skin cream/lotion;

- in case of ingestion get immediate medical attention;

- use face mask and goggles, and wear waterproof gloves and coveralls if handling, mixing or applying fire suppression chemicals;

- avoid inhalation of chemical vapors and work in well-ventilated areas;

- do not flush equipment near domestic or natural water supplies;

- locate chemical mixing and loading areas where natural water contact is minimal;

- leave at least 50 meters buffer between the chemical source and the water body;

- spills must be cleaned immediately;

- personnel must be properly trained before they come in contact with these products;

- personnel applying the chemicals from the ground should be able to stand in untreated areas as they proceed;

- keep the public to a safe distance when aerial drops are performed; and

- drop retardants from a sufficient height to insure breakup before reaching the ground.

Fire retardants can potentially have detrimental ecological effects if used injudiciously. The following guidelines are considered critical in reducing possible environmental impacts:

- inform all personnel of the potential problems that can be caused by retardants and foams in water bodies;

- exercise preplanning (e.g., consult with fishery experts, become familiar with important aquatic resources, locate safe routes for hauling chemicals, consider how to locate firelines away from stream banks);

- avoid direct application or drops into rivers, streams, lakes or lakeshores;

- be cautious if using chemicals in watersheds where fish hatcheries are located;

- be alert for instances of animal, fish or other aquatic organism kill;

- notify authorities promptly of any aquatic wildlife kill or spill into a water body;

- report reactions of other wildlife, particularly birds, in retardant drop areas, whether along streams or on the hillsides; and

- dipping from rivers or lakes with helicopters may cause problems to threatened and endan- gered species due to chemical residues.

Depending on the land management objectives, a manager may vary his/her decisions about using fire suppression chemicals. In a high-value and high-hazard forest, unlimited use of fire chemicals may be justified to control a catastrophic wildfire. Where conservation of natural ecosystems is of prime concern, use of fire retardants may be conditional, and sometimes, entirely unacceptable. Particularly sensitive sites, such as endangered species habitat, may warrant local restrictions on the use of those fire suppression chemicals that pose the greatest threat to aquatic wildlife.

If excessive smoke production is a critical air quality issue, then ammonium sulfate products will be more satisfactory. If more complete consumption of fuel is desired, ammonium sulfate will also be preferable. If retarding the fire with minimum after-glow is required, then ammonium phosphate products will be better (Hardy, 1977). Fire suppression personnel should carefully mix and apply these chemicals, following standard procedures to avoid accidents and minimize the risk for harmful effects. Some risks may not be eliminated, but these risks must be weighed against the necessity of fire control activities. Except in the case of a severe accident, the effects of the fire retardant chemicals are generally no more harmful than the effects of the fire itself.

Fire management officers must select fire control techniques which will achieve the appropriate balance between environmental damage caused by fire and that caused by fire suppressions practices. Trade-offs that require orthological and continuous decision-making include: i) use of retardants versus mechanical fire control techniques, ii) use of retardants versus no control efforts, and iii) taking versus not taking a risk in placing retardants accurately in critical spots (Hardy, 1977). Keys to sound decisions and successful applications of retardants in each case are advance/proper planning before the fire, as well as taking educated/intelligent risks during the fire. Modern technology must be combined with existing knowledge of ecological effects on natural ecosystems, to ensure that the best possible management case-scenario is exercised. The end result would be an environmental policy of risk management that is far more desirable and efficient than a policy of crisis management. 


\section{ACKNOWLEDGEMENTS}

The author wishes to acknowledge the invaluable advice and assistance provided for this work by Robert E. Burgan and Patricia L. Andrews of the Intermountain Fire Sciences
Laboratory in Missoula, Montana, USA, and the support from the Ministry of Agriculture in Greece, the NATO Science-for-Stability Program and the European Commission DG-XI in Brussels.

\section{REFERENCES}

Blahm, T.H. and Snyder, G.R. (1974), Effect of chemical fire retardants on the survival of juvenile Salmonids, National Marine Fisheries Service, Prescott, Oregon, USA.

Blakely, A.D. (1990), Combustion recovery of flaming pine needle fuel beds sprayed with water/MAP mixtures, USDA For. Serv. Res. Pap. INT-421, Ogden, Utah, USA.

Bradstock, R., Sanders, J. and Tegart, A. (1987), Short-term effects on the foliage of a eucalypt forest after an aerial application of a chemical fire retardant, Australian Forestry, 50, 71-80.

George, C.W. (1975), Fire retardant ground distribution patterns from the CL-215 air tanker, USDA For. Serv. Res. Pap. INT-165, Ogden, Utah, USA.

Hardy, C.E. (1977), Chemicals for forest fire fighting, $3^{\text {rd }}$ edition, National Fire Protection Association, Boston, Massachusetts, USA.

Johnson, C.W. and George, C.W. (1990), Relative corrosivity of currently approved wildland fire chemicals, USDA For. Serv. Res. Pap. INT-437, Ogden, Utah, USA.

Labat-Anderson Inc. (1994a), Human health risk assessment: chemicals used in wildland fire suppression, C. Boivin, project manager, Arlington, Virginia, USA.

Labat-Anderson Inc. (1994b), Ecological risk assessment: chemicals used in wildland fire suppression. C. Boivin, project manager, Arlington, Virginia, USA.

Labat-Anderson Inc. (1994c), Risk comparison of uncontrolled wildfires and the use of fire suppression chemicals, C. Boivin, project manager, Arlington, Virginia, USA.

Larson, J.R. and Duncan, D.A. (1982), Annual grassland response to fire retardant and wildfire, Journal of Range Management, 35, 700-703.

Norris, L.A., Hawkes, C.L., Webb, W.L., Moore, D.G., Bollen, W.B. and Holcombe, E. (1978), A report of research on the behavior and impact of chemical fire retardants in forest streams, Forestry Sciences Laboratory, PNW Forest and Range Experiment Station, Corvallis, Oregon, USA.

NWCG Fire Equipment Working Team (1992), Foam vs. fire: primer, National Wildfire Coordinating Group, NFES 2270, San Dimas, California, USA.

NWCG Fire Equipment Working Team (1993), Foam vs. fire: class A foam for wildland fires, $2^{\text {nd }}$ edition, National Wildfire Coordinating Group, NFES 2246, San Dimas, California, USA.

NWCG Fire Equipment Working Team (1995a), Interagency retardant base planning guide-fixed and rotor wing, National Wildfire Coordinating Group, NFES 1259, San Dimas, California, USA.

NWCG Fire Equipment Working Team (1995b), Lot acceptance, quality assurance, and field quality control for fire retardant chemicals, $5^{\text {th }}$ edition, National Wildfire Coordinating Group, NFES 1245, San Dimas, California, USA.

Petherick, J. (1990), Industrial hygiene report, Resource Center for Occupational Health and Safety, Lakehead University, LU90-172, Thunder Bay, Ontario, Canada.

Pyne, S.J., Andrews, P.L. and Laven, R.D. (1996), Introduction to wildland fire, $2^{\text {nd }}$ edition, John Wiley \& Sons, Inc., New York.

Van Meter, W.P. and Hardy, C.E. (1975), Predicting effects on fish of fire retardants in streams, USDA For. Serv. Res. Pap. INT-166, Ogden, Utah, USA. 